\title{
Norbornene-Ethylene Copolymers Studied by Non-Destructive Methods
}

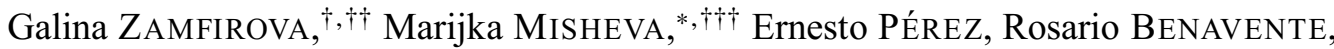 \\ María L. Cerrada, Nikolaj Djourelov, ${ }^{*}$ Mania Kresteva, ${ }^{*}$ and José M. Pereña \\ Instituto de Ciencia y Tecnología de Polímeros (CSIC), Juan de la Cierva 3, 28006 Madrid, Spain \\ "Sofia University “Kl. Ohridsky”, Faculty of Physics, Department of General Physics, \\ James Bourchier blvd. 5, 1126 Sofia, Bulgaria
}

(Received January 31, 2002; Accepted September 20, 2002)

\begin{abstract}
Norbornene-ethylene copolymers with relatively high norbornene content, synthesised using different metallocene catalysts, were studied by Microhardness methods and Positron Annihilation Lifetime Spectroscopy. It has been established that plastic and elastic properties as well as free volume of the investigated materials do not depend linearly on the norbornene content since the different molecular structures, as a result of the various catalytic systems used, have also an important influence on those parameters. Vickers microhardness and plastic properties of the samples investigated are not sensitive to the quantity of ethylene blocks and are influenced predominantly by micromechanical properties of polymer chains. Vickers microhardness is not sensitive either to dimensions and quantity of the pores or to the free volume. On the other hand, long ethylene sequences are related to total microhardness, i.e., during penetration they contribute to the elastic deformation. The sizes, distribution and quantity of the nanopores have been determined and explained in relation to the structure of the norbornene-ethylene copolymers.

KEY WORDS Norbornene-Ethylene Copolymers / Microhardness / Positron Annihilation / Nanopores / Free Volume /
\end{abstract}

Norbornene-ethylene (N-E) copolymers possess a relatively high glass transition temperature and improved transparency, stability against chemical degradation, impact resistance, toughness, flexibility, water vapour impermeability and processability. That is why they are very appropriate and extremely useful for optical applications, electrical appliances, automotive parts, containers, bottles, tough films, compact disks, etc.

Recently, there have been many articles devoted to the investigation of the structure and properties of norbornene-ethylene copolymers using standard investigative methods such as DSC, WAXS, DMTA, NMR, FT-IR and Raman spectroscopy. ${ }^{1-7}$ The most interesting and disputable issue is the relationship between the copolymer microstructure (that is influenced by the type of catalyst used in synthesising $\mathrm{N}-\mathrm{E}$ copolymers) and the norbornene content.

In this work both Microhardness $(M H)$ and Positron Annihilation Lifetime Spectroscopy (PALS) are also used as appropriate methods of investigation for this class of amorphous copolymers.

Microhardness is not only a routine measurement of the material hardness, but in recent years it has developed as an investigation method and adequate tool for determining the structure and mechanical properties of polymeric materials. It has been established that Vick- ers microhardness is sensitive to many structural parameters as well as to the mechanical behaviour. Therefore, as a method, it occupies an intermediate place between typical structural investigative methods and classical mechanical measurements, and consequently acts as a connecting link between both. ${ }^{8-15}$ Microhardness measurements carried out in the present work include that of Vickers microhardness (MHV), connected with the irreversible component of the deformation, and total microhardness $(M H T)^{16}$ connected with the total deformation.

Positron Annihilation Lifetime Spectroscopy (PALS) is a modern method for direct investigation of the amorphous phase structure. In recent years it is widely used to study the free-volume holes in polymers, which are due to their structural disorder. The evaluation of freevolume hole sizes is based on the fact that positron $\left(\mathrm{e}^{+}\right)$ and ortho-positronium (o-Ps) lifetimes are determined by the pore dimensions at which the annihilating particles are trapped. Supposing an infinite spherical potential model the relationship between the $o$-Ps lifetime $\tau_{\mathrm{o}-\mathrm{Ps}}$, , and the hole radius $R$, is given by the EldrupNakanishi formula: ${ }^{17,18}$

$$
\tau_{\mathrm{o}-\mathrm{Ps}}=1 / \lambda_{\mathrm{B}}=1 / 2\left[1-R / R_{0}+(1 / 2 \pi) \sin \left(2 \pi R / R_{0}\right)\right]^{-1}
$$

where $\tau_{\mathrm{o}-\mathrm{Ps}}$ and $R$ are in nanoseconds (ns) and $\AA$, re-

\footnotetext{
${ }_{\dagger}$ To whom correspondence should be addressed (E-mail: ictz351@ictp.csic.es).

${ }^{\dagger}$ Permanent Address: Higher Institute of Transport Engineering “T. Kableshkov”, Geo Milev str., 158, 1574 Sofia, Bulgaria.

${ }^{\dagger \dagger}$ E-mail: misheva@phys.uni-sofia.bg.
} 
Table I. Type of catalyst, glass transition temperature, $T_{\mathrm{g}}$, norbornene content and the prevailing sequences, determined by NMR investigations, ${ }^{5}$ for the different samples

\begin{tabular}{|c|c|c|c|c|c|c|}
\hline \multirow[t]{2}{*}{ Sample } & \multirow[t]{2}{*}{ Catalyst } & \multirow{2}{*}{$\begin{array}{c}\boldsymbol{T}_{\mathrm{g}} \\
\left({ }^{\circ} \mathrm{C}\right)\end{array}$} & \multirow{2}{*}{$\begin{array}{c}\boldsymbol{N} \\
(\mathrm{mol} \%)\end{array}$} & \multicolumn{3}{|c|}{$\begin{array}{l}\text { The most characteristic } \\
\text { norbornene sequences }\end{array}$} \\
\hline & & & & Alternating & Meso dyads & Blocks \\
\hline A & $r a c-\mathrm{Et}(\mathrm{Ind})_{2} \mathrm{ZrCl}_{2}$ & 173 & 55 & ++ & ++++ & + \\
\hline B & rac- $-\mathrm{Me}_{2} \mathrm{Si}(\mathrm{Ind})_{2} \mathrm{ZrCl}_{2}$ & 168 & 58 & + & ++++ & ++ \\
\hline $\mathrm{C}$ & $\mathrm{rac}-\mathrm{Me}_{2} \mathrm{Si}(\mathrm{B}-\mathrm{Ind})_{2} \mathrm{ZrCl}_{2}$ & 194 & 54 & + & ++++ & + \\
\hline $\mathrm{D}$ & rac $-\mathrm{Me}_{2} \mathrm{Si}(2 \mathrm{Me}-\mathrm{Ind})_{2} \mathrm{ZrCl}_{2}$ & 148 & 47 & $\begin{array}{l}++++ \\
\text { (isotactic) }\end{array}$ & + & + \\
\hline $\mathrm{E}$ & $r a c-\mathrm{Me}_{2} \mathrm{Si}(2 \mathrm{Me}-\mathrm{B}-\mathrm{Ind})_{2} \mathrm{ZrCl}_{2}$ & 125 & 60 & ++ & ++ & ++++ \\
\hline $\mathrm{F}$ & $\mathrm{Me}_{2} \mathrm{C}(\mathrm{Flu})(\mathrm{Cp}) \mathrm{ZrCl}_{2}$ & 156 & 58 & $\begin{array}{l}+++ \\
\text { (syndiotactic) }\end{array}$ & $\begin{array}{l}+++ \\
\text { (racemic) }\end{array}$ & \\
\hline
\end{tabular}

spectively; $\lambda_{\mathrm{B}}=2 \mathrm{~ns}^{-1}$ is the spin average $P_{\mathrm{S}}$ annihilation rate; and $R_{0}=R+\Delta R$, where $\Delta R=1.66 \AA$, is an empirically determined thickness of the electronic layer on pore walls.

\section{EXPERIMENTAL}

\section{Materials and Samples}

The materials studied are several norborneneethylene (N-E) copolymers with relatively high norbornene content, synthesised using different metallocene catalysts. ${ }^{10}$ The type of catalyst, glass transition temperature, $T_{\mathrm{g}}$, norbornene content as well as the prevailing sequences, determined by NMR investigations, ${ }^{5}$ are listed in Table I. The molecular weights, $M_{\mathrm{w}}$, of the samples range from 1 to $2 \times 10^{5}$, while their polymolecularity indices are around 2 , as usual in metallocene polymers. ${ }^{5,7}$ The ethylene-norbornene stereosequences most peculiar for each type of copolymer are shown in the Scheme 1.

Films of the samples studied were prepared by pressing the powder material under $16-20 \mathrm{kN}$ for $5 \mathrm{~min}$ at temperatures $35-40^{\circ} \mathrm{C}$ above the corresponding $T_{\mathrm{g}}$. Under these conditions good films were obtained. The temperature was kept as low as possible in order to minimize the degradation of the copolymers, especially in the cases of higher $T_{\mathrm{g}}$.

\section{Microhardness}

Microhardness measurements were performed at room temperature on a microhardness tester mhp-160, attached to a NU-2 microscope. The applied loads were between 1.25 and $160 \mathrm{~g}$. The indentor is a regular square pyramid with top angle $136^{\circ}$. The projected diagonal lengths of the indentation at loaded and unloaded state were determined.

The following microhardness characteristic were measured:

1. Vickers microhardness $(M H V)$, which represents the local plastic resistance of the material against a pen-

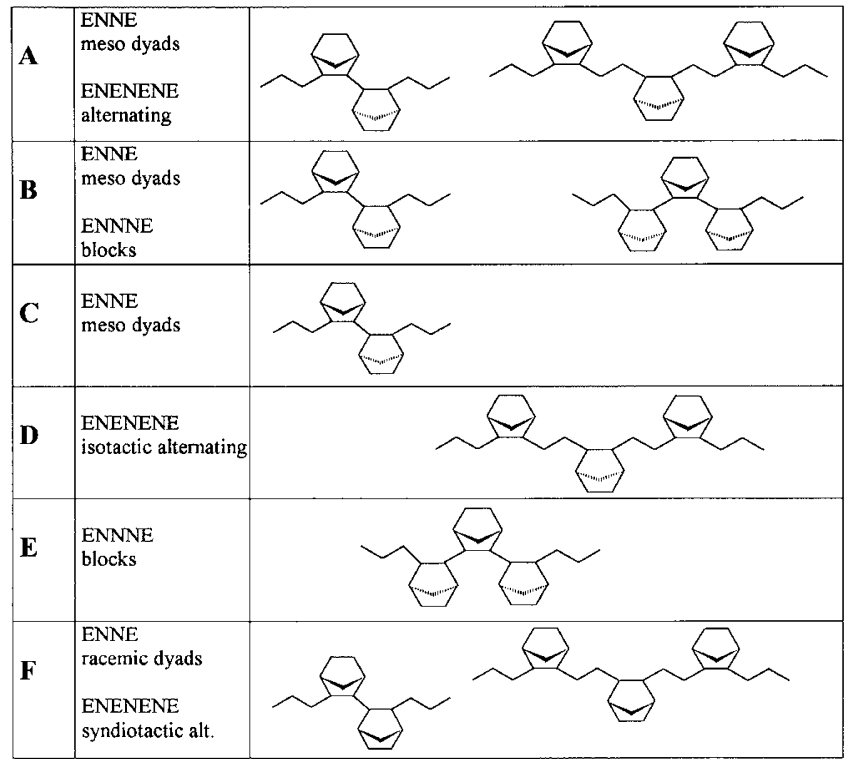

Scheme 1.

etration. It is calculated on the basis of the applied load, $P$, and the mean diagonal length of impression after removing the pyramidal indentor, $\mathrm{d}$ :

$$
M H V=k P / \mathrm{d}^{2}
$$

It turned out that the measuring of the sample B by microhardness methods was very imprecise, due to the blurred edges of the imprint. That is why it is excluded from some of the figures.

2. Total microhardness $(M H T)$. This microhardness parameter is defined on the analogy of the $M H V$ by the equation: ${ }^{16}$

$$
M H T=k P / D^{2}
$$

where $D$ is the diagonal of the indentation under the load in $\mu \mathrm{m}, k=18544$ is a geometrical constant connected with the indentor shape and $P$ is the applied load in $\mathrm{g}$. Thus, $M H T$ is a measure for the total material resistance against the deformation under the indentor, and is connected with the total deformation. 


\section{PALS}

The lifetime spectrometer was a standard fast-fast coincidence apparatus, which provides a time resolution of $c a .270 \mathrm{ps}$ for the full width at half maximum. The positron source was ${ }^{22} \mathrm{NaCl}$ between two thin $(\approx$ $1 \mathrm{mg} \mathrm{cm}^{-2}$ ) Kapton foils. Usually a sandwich type of sample-source is used in positron lifetime measurements. In this case, however, the material available was in limited quantity to prepare samples thick enough to absorb all positrons. Because of this, two well-annealed and chemically etched $\mathrm{Cu}$ discs have comprised the sample-source ensemble. The part of positrons annihilating in the source and in $\mathrm{Cu}$ discs was taken into account during the spectra processing, and was calculated by the program "Layer". ${ }^{19}$ The statistics of positrons annihilating only in samples studied were of the order of $10^{6}$ for each spectrum. As a rule 6-7 spectra were recorded for each sample. The spectra were analysed in two ways: assuming the existence of a few discrete positron lifetimes, or a distribution of annihilation rates. Supposing 3 or 4 discrete lifetime components, PATFIT code was applied. ${ }^{20}$ In PATFIT code it is considered that the positrons annihilate in several strictly defined states. The positron lifetimes and their relative intensities are extracted by a least-squares analysis of measured lifetime spectra.

The lifetimes $\tau_{\mathrm{i}}$ and their relative intensities $I_{\mathrm{i}}$, used for further discussion, represent weighted means of values obtained from all spectra, registered for a given sample. These spectra were also summed to obtain one spectrum for each sample with great statistics, which were analysed by the CONTIN program ${ }^{21,22}$ to get the distribution of pore sizes (radii or volumes). As a reference spectrum, the positron lifetime spectrum of well annealed $\mathrm{Cu}$ samples ( $\tau=122 \mathrm{ps}, I>99 \%)$ was used.

The lifetime spectrum $N(t)$ in the case of highly inhomogeneous materials can be presented by the convolution $\left(^{*}\right)$ of the experimental resolution function $I(t)$, and the decay curve of positrons $C(t)$ :

$$
N(t)=N_{\mathrm{s}} I(t)^{*} C(t) ; C(t)=\int \lambda \alpha(\lambda) \exp (-\lambda t) \mathrm{d} \lambda
$$

Here, $N_{\mathrm{S}}$ is the total number of the annihilation events and $\alpha(\lambda)$ is the annihilation rate probability density function (PDF). The fraction of positrons annihilating with rates between $\lambda$ and $\lambda+\mathrm{d} \lambda$ is given by $\alpha(\lambda) \mathrm{d} \lambda$ with $\int \alpha(\lambda) \mathrm{d} \lambda=1$. The difference between mathematical models in PATFIT and CONTIN is only about the mode of $C(t)$.

The fraction of positrons $F(R)$, annihilating in pores with radii between $R$ and $R+\mathrm{d} R$ is: ${ }^{23}$

$$
F(R) \mathrm{d} R=\left|\left(2 \Delta R / R_{0}^{2}\right)\left(\cos \left(2 \pi R / R_{0}\right)-1\right) \alpha(\lambda)\right| \mathrm{d} R(5)
$$

The variation of the fractional free volume $F_{\mathrm{v}}$ is rep- resented in this paper by the parameter $F_{\mathrm{r}}=V_{\mathrm{f}} I_{\mathrm{o}-\mathrm{Ps}}$ where $I_{\mathrm{o}-\mathrm{Ps}}(\%)$ is the intensity of $o$-Ps lifetime component(s) $\tau_{3}$ (and $\tau_{4}$ ), and $V_{\mathrm{f}}=4 \pi R^{3} / 3$ is the pore volume. $F_{\mathrm{v}}$ is given by $F_{\mathrm{v}}=V_{\mathrm{p}} /\left(V_{\mathrm{p}}+V_{\mathrm{m}}\right)$, where $V_{\mathrm{m}}$ and $V_{\mathrm{p}}$, are "occupied" and "free" volumes respectively. On the other side, according to ${ }^{23} F_{\mathrm{v}}=C V_{\mathrm{f}} I_{\mathrm{o}-\mathrm{Ps}}, C$ being an empirical constant. Obviously, the variation of the parameters $F_{\mathrm{r}}$ and $F_{\mathrm{v}}$ is identical, provided that $C$ is the same for all the materials studied.

\section{WAXS}

The WAXS studies were carried out on a TUR M62 diffractometer, using Co- $K \alpha$ radiation $(\lambda=1.788 \AA)$. The intensity distribution was presented as a function of $s=2 \sin \theta / \lambda$, where $\theta$ and $\lambda$ are the Bragg angle and wave length, respectively.

\section{RESULTS AND DISCUSSION}

Wide angle X-Ray patterns of the studied samples of $\mathrm{N}-\mathrm{E}$ copolymers are shown in Figure 1. As it can be seen, all samples are amorphous (in agreement with the DSC results, which show only the glass transition, irrespectively of the thermal treatment ${ }^{5}$ ). The amorphous halo of the polymers synthesised using catalysts A, B, and $\mathrm{C}$ is asymmetric with a hump from the side of low $s$ values (high d-spacings). At the same time the haloes of the polymers synthesised using catalysts D, E, and F are absolutely symmetric.

The distribution of pore radius PDFs obtained by PALS is presented in Figure 2. On the basis of these distributions, the samples studied could be classified into two groups: the first one, including samples A, $\mathrm{B}$, containing pores of two different sizes, and the sec-

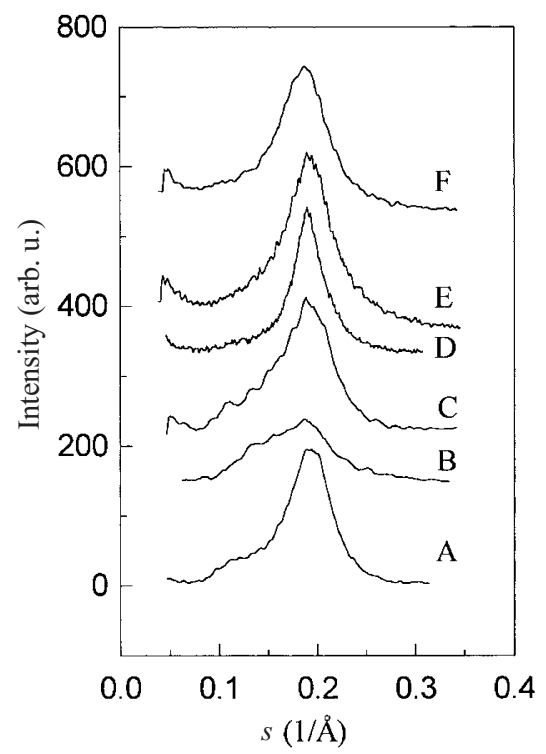

Figure 1. X-Ray patterns of N-E copolymers. 
Table II. Lifetimes $\tau_{\mathrm{i}}$ and their relative intensities $I_{\mathrm{i}}$, obtained by unconstrained 3 components analysis by PATFIT code

\begin{tabular}{ccccccc}
\hline Sample & $\tau_{1}(\mathrm{ps})$ & $I_{1}(\%)$ & $\tau_{2}(\mathrm{ps})$ & $I_{2}(\%)$ & $\tau_{3}(\mathrm{ps})$ & $I_{3}(\%)$ \\
\hline $\mathrm{A}$ & 150 & 32 & 422 & 43 & 2130 & 25 \\
$\mathrm{~B}$ & 156 & 45 & 496 & 30 & 2650 & 25 \\
$\mathrm{C}$ & 13 & 41.5 & 414 & 35.5 & 2220 & 23 \\
$\mathrm{D}$ & 13 & 43 & 39 & 35 & 2010 & 22 \\
$\mathrm{E}$ & 132 & 32 & 39 & 42 & 2070 & 26 \\
$\mathrm{~F}$ & 151 & 30 & 408 & 40 & 2006 & 30 \\
\hline
\end{tabular}

Table III. Results of unrestricted 4-component analysis of lifetime spectra of sample B by PATFIT code

\begin{tabular}{ccccccccc}
\hline Sample & $\tau_{1}(\mathrm{ps})$ & $I_{1}(\%)$ & $\tau_{2}(\mathrm{ps})$ & $I_{2}(\%)$ & $\tau_{3}(\mathrm{ps})$ & $I_{3}(\%)$ & $\tau_{4}(\mathrm{ps})$ & $I_{4}(\%)$ \\
\hline $\mathrm{B}$ & 125 & 34 & 369 & 38 & 1900 & 18 & 3200 & 10 \\
\hline
\end{tabular}

Table IV. Parameters obtained from PALS (mean positron lifetimes $\tau_{\mathrm{m}}$, pore radii $R$, pore volumes $V_{\mathrm{f}}$, free volume parameters $F_{\mathrm{r}}$ ) and from WAXS (peak position $s$ and corresponding full width at half maximum $w$ of the main amorphous halo)

\begin{tabular}{cccccccc}
\hline \multirow{2}{*}{ Sample } & \multicolumn{4}{c}{ PALS measurements } & & \multicolumn{2}{c}{ WAXS measurement } \\
\cline { 2 - 4 } \cline { 7 - 8 } & $\tau_{\mathrm{m}}(\mathrm{ps})$ & $R(\AA)$ & $V_{\mathrm{f}}\left(\AA^{3}\right)$ & $F_{\mathrm{r}}=I_{3} \times V_{\mathrm{f}}\left(\AA^{3}\right)$ & & $s\left(\AA^{-1}\right)$ & $w\left(\AA^{-1}\right)$ \\
\hline $\mathrm{A}$ & 760 & 2.968 & 109.5 & 2740 & & 0.193 & 0.050 \\
$\mathrm{~B}$ & 882 & 3.380 & 161.9 & 4050 & & 0.185 & 0.065 \\
$\mathrm{C}$ & 711 & 3.042 & 117.8 & 2710 & & 0.193 & 0.055 \\
$\mathrm{D}$ & 639 & 2.863 & 98.2 & 2160 & & 0.190 & 0.036 \\
$\mathrm{E}$ & 745 & 2.909 & 103.1 & 2680 & & 0.191 & 0.056 \\
$\mathrm{~F}$ & 814 & 2.854 & 97.3 & 2920 & & 0.186 & 0.053 \\
\hline
\end{tabular}

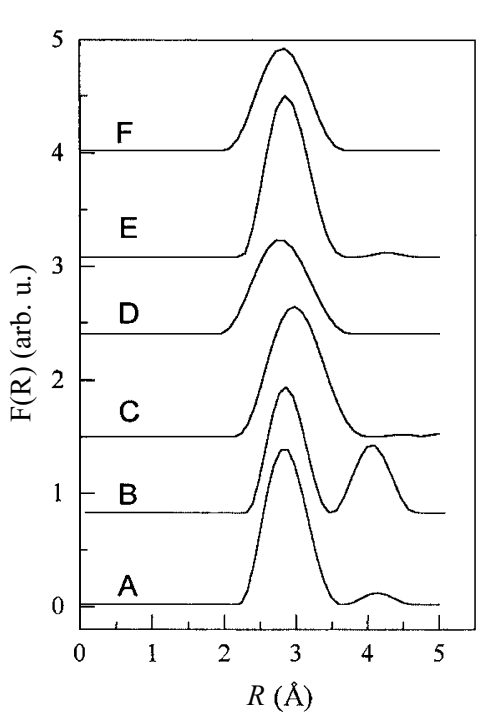

Figure 2. The distribution of pore radius obtained by PALS.

ond group which includes the other samples $(\mathrm{C}, \mathrm{D}, \mathrm{E}$, F) and displays a distribution of the pores only around one size. Samples $\mathrm{C}$ and $\mathrm{E}$ have a negligible small quantity of pores with greater dimensions, but nevertheless could be also related to the first group. According to reference $5, \mathrm{~A}, \mathrm{~B}$, and $\mathrm{C}$ are made up of mixtures of meso dyads, alternating sequences, and blocks of three or more norbornenes although the ENNE meso sequences prevail (see scheme 1 for the different predominant sequences).

From Figures 1 and 2 it seems that there is some relation between the existence of two kinds of holes and the observation of the two X-Ray haloes correspond- ing to two different intermolecular distances. However, more experiments are necessary in order to assess this relation.

The results obtained by unconstrained threecomponent decomposition of lifetime spectra by PATFIT are presented in Table II. All attempts of four unconstrained components fit of lifetime spectra by PATFIT, with exception of sample B, were unsuccessful. The results from the 4-components fit for sample B are given in Table III. The parameters obtained from PALS (mean positron lifetimes $\tau_{\mathrm{m}}$, pore radii $R$, pore volumes $V_{\mathrm{f}}$ and free volume parameters $F_{\mathrm{r}}$ ) as well as from WAXS (peak position $s$ and corresponding full width of half maximum $w$ of the main amorphous halo) are listed in Table IV.

Positron annihilation in poly(norbornene), a linear polymer of 2,2,1-bicyclo hept-2-ene, has been measured by Ujihira et al. ${ }^{24}$ At room temperature, the estimated radius of free-volume hole is $2.88 \AA$ which corresponds, according to formula (1), to a $\tau_{3}=2 \mathrm{~ns}$. For polyethylene, these parameters are somewhat larger, in the range of 3-3.2 $\AA$ and $2.2-2.5 \mathrm{~ns}$ respectively. Therefore, the studied copolymers possess free volume holes with sizes closer to those of poly(norbornene).

When used as a comonomer, the bicyclic olefins such as norbornene impart rigidity to the main polymer chain. Because of this it could be assumed that both, sizes of the free-volume holes and their quantity $\left(I_{3}\right)$, might be directly proportional to norbornene content, what is not the present case. 


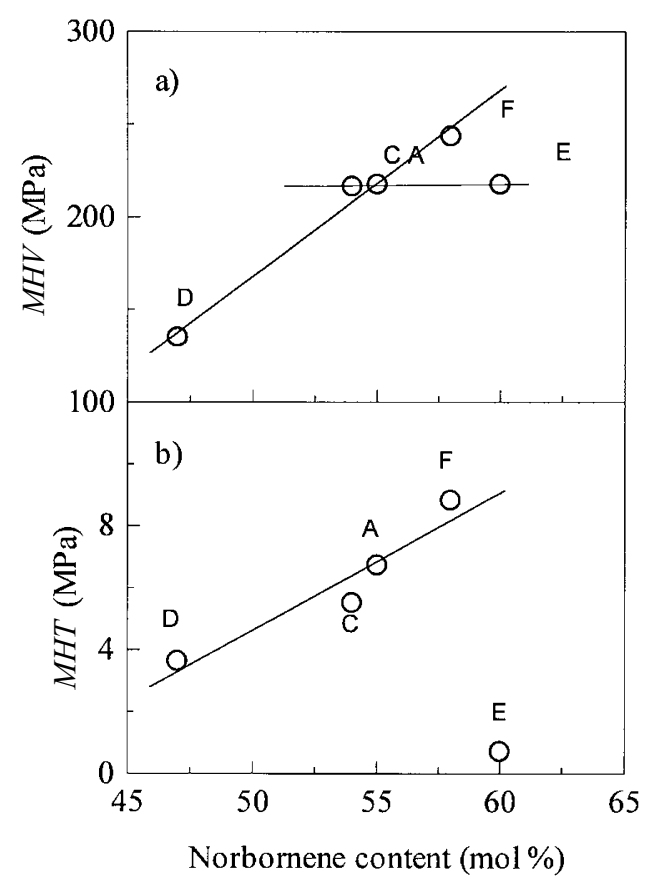

Figure 3. Vickers microhardness (a) and Total microhardness (b) as a function of the norbornene content.

Vickers microhardness, which depends on both the rigidity of the polymer chains and the free volume, is shown in Figure $3 \mathrm{a}$ as a function of the norbornene content. It can be seen that $M H V$ is almost the same for the polymers containing meso dyads $(\mathrm{C}, \mathrm{A}, \mathrm{E})$ and is not sensitive to other sequences included in these samples. In sample A there are also alternating groups. In E blocks prevail, but they include actually meso dyads. So $M H V$ is not sensitive to block sequences. It seems that meso dyads and blocks have the same response to plastic deformation, while the alternating groups do not have an additional influence on it. When only alternating groups are present (sample D) $M H V$ is considerable lower. On the other hand, sample $\mathrm{F}$ has a higher $M H V$ and it is due to racemic sequences, not to the presence of alternating groups.

From Figure $3 b$ it could be seen that, as distinct from plastic deformation resistance $(M H V)$, the alternating groups and blocks influence the resistance against the total deformation (MHT). At first sight it seems that alternating groups increase a little the elastic resistance (sample A), while blocks rapidly decrease it (sample E). Sample E shows a relatively good resistance against plastic deformation but a very small resistance against total deformation, i.e., it shows good elastic properties.

Figure 4 shows at first glance an illogical monotonically increasing of $M H V$ and $M H T$ with increasing of the fractional free volume, with the exception of the sample E (with prevailing block sequences). If we take into account the mutual arrangement of ethylene groups it could be expected that in the sample E (in which nor-

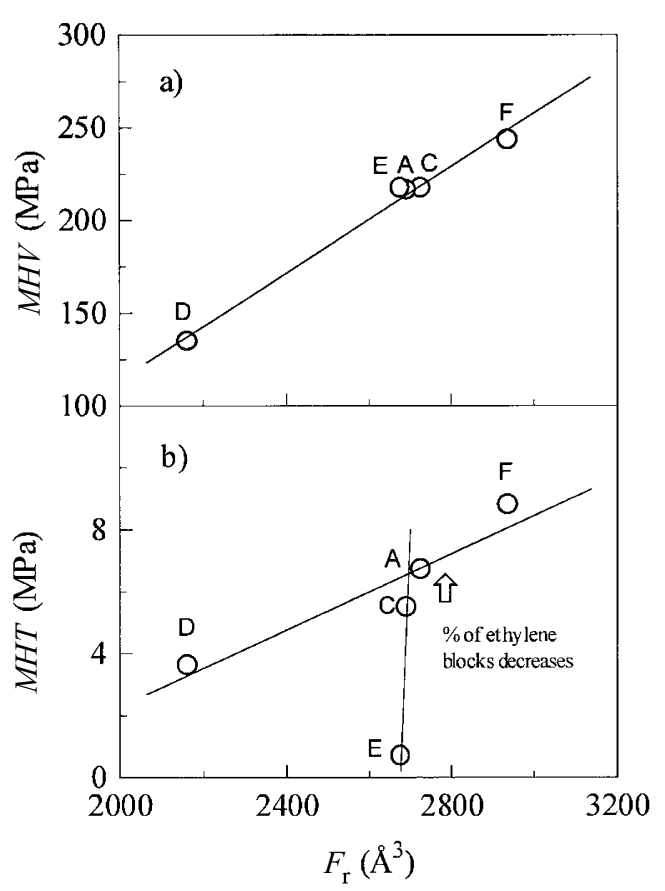

Figure 4. Vickers microhardness (a) and Total microhardness (b) $v s$. PALS parameter $F_{\mathrm{r}}=V_{\mathrm{f}} I_{\mathrm{o}-\mathrm{Ps}}$, proportional to the fractional free volume $F_{\mathrm{v}}$.

bornene blocks are dominant) the ethylene blocks (sequences) dominate also. From Figure $4 \mathrm{~b}$ it could be clearly seen that through the sequence, E, C, A, which have an almost equal free volume, $M H T$ increases. It is due to decreasing content of ethylene blocks. Sample $\mathrm{E}$ has the most of the ethylene blocks; in sample $\mathrm{C}$, where dyads prevail, the probability for occurring long ethylene blocks decreases; in sample A there are dyads and alternating groups, which greatly constrain the occurrence of ethylene blocks. Therefore the ethylene blocks, which carry the properties of PE, including its smaller resistance against the penetration, increase the elasticity of the polymers in the order E, C, A. In other words, ethylene blocks influence the elastic properties and do not influence the plastic ones. Hence it can be concluded that $M H V$ is not sensitive to the quantity of the ethylene blocks, while $M H T$ is sensitive to them.

Only on the basis of Figure 3a, it could be speculatively said that $M H V$ increases with the increasing of the norbornene content. But the dependence $F_{\mathrm{r}} v s$. norbornene content (Figure 5) has the same tendency as Figure 3a. It means that $M H V$ does not depend linearly on $F_{\mathrm{r}}$ but on the molecular structure and, as a consequence of it, the molecular structure influences both values, $M H V$ and $F_{\mathrm{r}}$, following the same trend. In other words, $M H V$ and free volume measurements have a similar sensitivity to micromechanical properties.

PALS measurements give also possibility to estimate the concentration of pores with different radii. Figure 6 


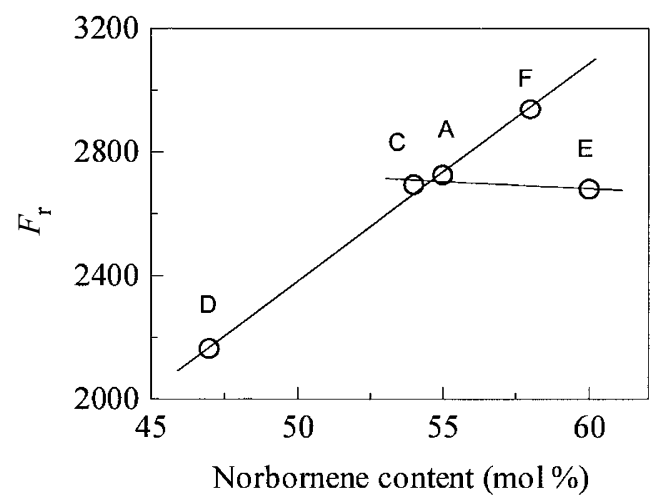

Figure 5. PALS parameter $F_{\mathrm{r}}=V_{\mathrm{f}} I_{\mathrm{o}-\mathrm{Ps}} v s$. norbornene content.

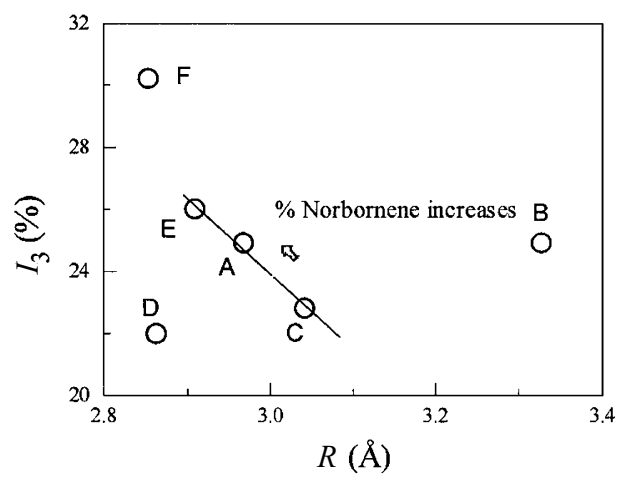

Figure 6. Pore dimension $(R)$ and their intensity $\left(I_{3}\right)$ for the $\mathrm{N}-$ E copolymers studied, obtained by PALS.

shows the change of the pore dimension $(R)$ and their intensity $\left(I_{3}\right)$ in the different samples. It can be observed that:

- Sample D (alternating groups) possesses pores with the smallest dimension and smallest quantity of them. It could be supposed that it is due to its alternating molecular structure whose better regularity leads to more compact structure. This sample has also the lowest value at the width of half-maximum $w$ (see Table IV).

- Sample F, with prevailing racemic meso dyads and syndiotactic alternating groups, possesses the smallest pores, but a big quantity of them.

- Sample B possesses the holes with largest dimensions and medium quantity of them. X-Ray patterns give for this sample the largest value of the full width at half maximum.

- For samples ordered C, A, E, norbornene content increases. With increasing the norbornene content, $R$ decreases but $I_{3}$ increases. As a result, free volume and $M H V$ remain almost the same (Figure 3a and Figure 5) and hence the results of these three samples can be discussed as follows:

- Sample E has the highest norbornene content, but it is grouped predominantly in blocks. The flexible ethylene blocks contribute to the smaller dimensions of the pores.
- Sample C has the smallest norbornene content but it is grouped predominantly in meso dyads without alternating groups, which contribute to bigger dimensions but smaller quantity of pores.

- Sample A, which contains meso dyads and alternating groups, occupies the medium position.

From all these results it can be summarised that $M H V$ and consequently plasticity depend predominantly on molecular structure and are not sensitive to dimensions and quantity of the pores. For example, sample D has small pores and small quantity of them, but nevertheless it has a small microhardness because the small rigidity of the chains, where the alternating isotactic sequences prevail.

\section{CONCLUSIONS}

1. For norbornene-ethylene copolymers microhardness and consequently plastic and elastic properties of the investigated materials do not depend linearly on the norbornene content, since the different molecular structures, as a result of catalytic systems used in the synthesis, have also an important influence on those parameters.

2. Long ethylene sequences are related to total microhardness, i.e., during penetration they contribute to the elastic deformation. MHV and plastic properties are not sensitive to the quantity of ethylene blocks.

3. Structural peculiarities of the polymer chain in norbornene-ethylene copolymers influence free volume as well as plastic resistance against the penetration.

4. Vickers microhardness is influenced predominantly by micromechanical properties of polymer chains. It is not sensitive either to dimensions and quantity of the pores or to the free volume.

5. The sizes, distribution and quantity of the nanopores has been determined and explained in relation to the structure of norbornene-ethylene copolymers.

Acknowledgments. We thank the NATO Science Committee for the invited scientist grant awarded to one of us (G. Zamfirova). Financial support from the Bulgarian Academy of Sciences and the Spanish Council for Scientific Research (CSIC) (project 2001 BG 0003) is gratefully acknowledged. The support from the European Commission (TMR Network ERB FMRX CT97-0116 GLASSCYCLICS and COST Action D17, WG D17/0004/00) and from the Ministerio de Ciencia y Tecnología (project MAT2001-2321) is also acknowledged. We thank Drs. I. Tritto and L. Boggioni for providing us with the $\mathrm{N}-\mathrm{E}$ copolymers. 


\section{REFERENCES}

1. J. Scheirs and W. Kaminsky, Eds., "Metallocene-based Polyolefins. Preparation, Properties and Technology", John Wiley \& Sons, Inc., New York, N.Y., 2000, vol.1 and 2.

2. B. A. Harrington and D. J. Crowther, J. Mol. Catal. A: Chem., 128, 79 (1998).

3. D. Ruchatz and G. Fink, Macromolecules, 31, 4669 (1998).

4. I. Tritto, L. Boggioni, M. C. Sacchi, P. Locatelli, D. R. Ferro, and A. Provasoli, Macromol. Rapid Commun., 20, 279 (1999).

5. J. Forsyth, J. M. Pereña, R. Benavente, E. Pérez, I. Tritto, L. Boggioni, and H. H. Brintzinger, Macromol. Chem. Phys., 202, 614 (2001).

6. J. Forsyth, T. Scrivani, R. Benavente, C. Marestin, and J. M. Pereña, J. Appl. Polym. Sci., 82, 2159 (2001).

7. T. Scrivani, R. Benavente, E. Pérez, and J. M. Pereña, Macromol. Chem. Phys., 202, 2547 (2001).

8. F. J. Baltá-Calleja, J. Martínez Salazar, and D. R. Rueda, in "Encyclopedia of Polymer Science and Engineering", John Wiley \& Sons, Inc., New York, N.Y., 1986, vol. 6, p 614.

9. F. J. Baltá-Calleja, Adv. Polym. Sci., 66, 117 (1985).

10. V. Lorenzo, J. M. Pereña, and JMG Fatou, Angew. Makromol. Chem., 172, 25 (1989).

11. F. J. Baltá-Calleja and H. G. Kilian, Colloid Polym. Sci., 263, 697 (1985).
12. S. Fakirov, F. J. Baltá-Calleja, and M. Krumova, J. Polym. Sci., Polym. Phys. Ed., 37, 1413 (1999).

13. S. Fakirov, M. Krumova, and D. R. Rueda, Polymer, 41, 3047 (2000).

14. J. M. Pereña, V. Lorenzo, G. Zamfirova, and A. Dimitrova, Polym. Test., 19, 231 (2000).

15. E. Amitay-Sadovsky and H. D. Wagner, J. Polym. Sci., Polym. Phys. Ed., 37, 523 (1999).

16. G. Zamfirova and A. Dimitrova, Polym. Test., 19, 533 (2000).

17. H. Nakanishi, S. J. Wang, and Y. C. Jean, in "Positron Annihilation Studies of Fluids", S. C. Sharma, Ed., World Scientific Publishing Co. Pte. Ltd., Singapore, 1987, p 292.

18. M. Eldrup, D. Lightbody, and J. N. Sherwood, Chem. Phys., 63, 51 (1981).

19. N. Djourelov and M. Misheva, J. Phys.: Condens. Matter, 8, 2081 (1996).

20. P. Kirkegaard, N. J. Pedersen, and M. Eldrup, "PATFIT-88", Risø Natl. Lab., Roskilde, Denmark, 1989.

21. S. W. Provencher, Comp. Phys. Commun., 27, 229 (1982).

22. R. Gregory, J. Appl. Phys., 70, 4665 (1991).

23. H. Nakanishi, Y. Y. Wang, Y. C. Jean, and T. C. Sandreczki, in "Positron Annihilation Studies of Fluids", S. C. Sharma, Ed., World Scientific Publishing Co. Pte. Ltd., Singapore, 1987, p 285.

24. J. Ujihira, H. L. Li, and K. Ito, Acta Phys. Pol., A, 95, 677 (1999). 